TITLE:

\title{
Hepcidin expression in liver cells: evaluation of mRNA levels and transcriptional regulation.
}

AUTHOR(S):

Kanamori, Yohei; Murakami, Masaru; Matsui, Tohru; Funaba, Masayuki

\section{CITATION:}

Kanamori, Yohei ...[et al]. Hepcidin expression in liver cells: evaluation of mRNA levels and transcriptional regulation.. Gene 2014, 546(1): 50-55

ISSUE DATE:

2014-08-01

URL:

http://hdl.handle.net/2433/188889

\section{RIGHT:}

C 2014 Elsevier B.V.; この論文は出版社版でありません。引用の際には 出版社版をご確認ご利用ください。; This is not the published version. Please cite only the published version. 
Hepcidin expression in liver cells: evaluation of mRNA levels and transcriptional regulation

Yohei Kanamori ${ }^{1}$, Masaru Murakami ${ }^{2}$, Tohru Matsui ${ }^{1}$ and Masayuki Funaba ${ }^{1 \star}$

${ }^{1}$ Division of Applied Biosciences, Kyoto University Graduate School of Agriculture, Kyoto 606-8502, Japan

${ }^{2}$ Laboratory of Molecular Biology, Azabu University School of Veterinary Medicine, Sagamihara 252-5201, Japan

Running title: Hepcidin expression in liver cells

*Corresponding author: Masayuki Funaba, Ph.D.

Division of Applied Biosciences

Kyoto University Graduate School of Agriculture

Kitashirakawa Oiwakecho, Kyoto 606-8502, Japan

Tel.: +81-75-753-6055

Fax: +81-75-753-6344

E-mail: mfunaba@kais.kyoto-u.ac.jp 


\section{Abstract}

Hepcidin produced in the liver negatively regulates intestinal iron absorption, and the bone morphogenetic protein (BMP) pathway is well-known to stimulate hepcidin expression. However, the regulation of hepcidin expression has not been fully elucidated. In this study, we evaluate different systems that can be used to determine how hepcidin expression is regulated. The basal expression of hepcidin in liver cell lines, such as HepG2 cells and Hepa1-6 cells, was lower than that in the liver and primary hepatocytes; the expression levels of hepcidin in the cell lines were near the limit of detection for RT-PCR and RT-qPCR analyses. Treatment with trichostatin A, RNAlater, or MG-132 enhanced the expression of hepcidin in HepG2 cells, suggesting that histone deacetylation, instability of mRNA, or proteosomal degradation of the protein(s) that positively regulate hepcidin expression may be responsible for the decreased expression of hepcidin in HepG2 cells. In luciferase-based reporter assays, BMP induced the transcription of a reporter, hepcidin(-2018)-luc, that contains nt -2018 through nt -35 of the hepcidin promoter in HepG2 cells and Hepa1-6 cells. However, BRE-luc, a representative reporter used to evaluate BMP signaling, was unresponsive to BMP in HepG2 cells. These results suggest that hepcidin transcription can be best evaluated in liver cell lines and that the hepcidin promoter senses BMP signaling with high sensitivity. The present study demonstrates that studies regarding the regulation of hepcidin expression at the mRNA level should be evaluated in primary hepatocytes, and liver cell lines are well-suited for studies examining the transcriptional regulation of hepcidin. 


\section{Abbreviations}

BMP, bone morphogenetic proteins; CMF, calcium and magnesium-free; HBSS, Hank's buffered salt solution; DMEM, Dulbecco's modified Eagle's medium, FBS, fetal bovine serum; ALK, activin receptor-like kinase; RT-PCR, reverse transcription-polymerase chain reaction; RT-qPCR, reverse transcription-quantitative polymerase chain reaction; Gapdh, glyceraldehyde-3-phosphate dehydrogenase ; pCMV- $\beta$ Gal, plasmid expressing $\beta$-galactosidase under the control cytomegalovirus promoter; SEM, standard error of the mean; Id1, inhibitor of differentiation 1; Hprt1, hypoxanthine phosphoribosyltransferase 1

Key words: hepcidin; mRNA; transcription; BMP; liver cells 


\section{Introduction}

The iron uptake of the body is tightly regulated through the modulation of its absorption from the intestine (Lee and Beutler, 2009). Ferric iron is reduced at the luminal site by intestinal cytochrome $b$, and ferrous iron is transferred into the enterocyte via the transmembrane protein divalent metal transporter-1. On the basolateral side, ferrous iron is exported from enterocytes to the circulatory system via ferroportin, and after being oxidized by the membrane bound ferroxidase hephaestin, iron is incorporated into transferrin (Ganz and Nemeth, 2012).

Hepcidin is a 25-amino acid antimicrobial peptide that serves as the central regulator of intestinal iron absorption (Lee and Beutler, 2009). Hepcidin binds to the iron exporter ferroportin and induces its endocytosis and proteolysis, thus preventing intestinal absorption of iron (Nemeth et al., 2004; De Domenico et al., 2007). Previous studies suggested that hepcidin activity is mainly regulated at the gene transcript level (Ganz and Nemeth, 2012). The ratio of intestinal iron absorption to iron intake decreases as dietary iron levels increase (Laftah et al., 2004), and this is achieved by the up-regulation of hepatic hepcidin expression (Kautz et al., 2008; Corradini et al., 2009). The current model suggests that hepcidin expression is transcriptionally regulated by the pathway induced by bone morphogenetic proteins (BMPs) such as BMP2, BMP4, BMP6 and BMP9 (Babitt et al., 2006, Truksa et al., 2006; Babbit et al., 2007; Muckenthaler, 2008; Lee and Beutler, 2009). Increased levels of iron have been shown to increase the hepatic expression of BMP6 (Kautz et al., 2008), and the disruption of BMP6 resulted in decreased hepatic hepcidin expression and the accumulation of iron in the liver (Andriopoulos et al., 2009; Meynard et al., 2009). However, factors other than the BMPs are also involved in modulating hepcidin expression (Muckenthaler, 2008; Lee and Beutler, 2009; Goodnough et al. 2012), indicating that the mechanisms governing hepcidin expression have not yet been fully elucidated. 
While exploring the factors that affect hepcidin expression, we noticed that hepcidin expression in liver cell lines is extremely low compared to that in the liver and primary hepatocytes, and this low level of expression makes it difficult to evaluate the regulation of hepcidin at the mRNA level. The main objective of this study is to clarify the differences of the hepcidin expression level among the livers, primary hepatocytes and liver cell lines. The present study provides information on cultured cell systems suitable for evaluating hepcidin expression.

\section{Materials \& methods}

\subsection{Animals and cell culture}

Animal experiments were approved by the Kyoto University Animal Experiment Committee or the Azabu University Animal Experiment Committee. Mouse and rat livers were obtained from normal adult C57BL/6 mice and Sprague-Dawley rats, respectively. Primary rat hepatocytes were isolated by collagenase digestion of livers from male Wistar rats weighing 200 to $300 \mathrm{~g}$. Livers were perfused from the portal vein to the incised inferior vena cava with calcium and magnesium-free (CMF) buffer consisting of $40 \mathrm{mM}$ Hepes, $\mathrm{pH} 7.4,120 \mathrm{mM} \mathrm{NaCl}, 5.4 \mathrm{mM} \mathrm{KCl}, 5.0 \mathrm{mM} \mathrm{NaHCO} 3$ and $5.6 \mathrm{mM}$ glucose supplemented with $100 \mathrm{U} / \mathrm{mL}$ penicillin, $100 \mu \mathrm{g} / \mathrm{mL}$ streptomycin and $250 \mathrm{ng} / \mathrm{mL}$ amphotericin $\mathrm{B}$ for $10 \mathrm{~min}$ at a rate of $\sim 12 \mathrm{~mL} / \mathrm{min}$ followed by perfusion with CMF buffer containing $0.05 \%$ collagenase (Wako, Tokyo, Japan) for $10 \mathrm{~min}$. Subsequently, hepatocytes were liberated into Hank's buffered salt solution (HBSS), i.e., $140 \mathrm{mM} \mathrm{NaCl}, 5.4 \mathrm{mM} \mathrm{KCl}, 0.34 \mathrm{mM} \mathrm{Na} \mathrm{HPO}_{4}, 0.44 \mathrm{mM} \mathrm{KH}_{2} \mathrm{PO}_{4}, 0.81 \mathrm{mM}$ $\mathrm{MgSO}_{4} \cdot 7 \mathrm{H}_{2} \mathrm{O}, 1.3 \mathrm{mM} \mathrm{CaCl} 2,4.2 \mathrm{mM} \mathrm{NaHCO} 3$ and $5.6 \mathrm{mM}$ glucose supplemented with $100 \mathrm{U} / \mathrm{mL}$ penicillin, $100 \mu \mathrm{g} / \mathrm{mL}$ streptomycin and $250 \mathrm{ng} / \mathrm{mL}$ amphotericin $\mathrm{B}$. After cell recovery by centrifugation at $50 \times g$ for $2 \mathrm{~min}$, the cells were washed with 
HBSS three times and resuspended in Dulbecco's modified Eagle's medium (DMEM) with $10 \%$ fetal bovine serum (FBS) and antibiotics. Cells (>90\% hepatocytes by microscopy) were seeded on collagen-coated plates at $1.5 \times 10^{5}$ cells per well in 12-well plates. After attachment, the medium was replaced with the same medium, and the cells were incubated for $24 \mathrm{~h}$. Then, cells were treated with or without BMP2 (4 nM; R \& D Systems, Minneapolis, MN, USA) in the presence or absence of cycloheximide $(0.5 \mu \mathrm{g} / \mathrm{mL})$ for $12 \mathrm{~h}$.

HepG2 hepatoma cells, Hepa1-6 hepatoma cells and 3T3-L1 preadipocytes were cultured in DMEM with 10\% FBS and antibiotics. For the luciferase-based reporter assays, these cells were transiently transfected using PolyFect transfection reagent (Qiagen, Valencia, CA, USA) or polyethylenimine Max reagent (Polysciences, Warrington, PA, USA), according to the manufacturers' protocols. At $24 \mathrm{~h}$ post-transfection, the cells were pre-treated with or without LDN-193189 (100 nM), an inhibitor of the BMP type I receptor (Cuny et al., 2008), for 15 min before BMP2 (4 $\mathrm{nM}$ ) treatment for $16 \mathrm{~h}$. To evaluate the expression of constitutively active activin receptor-like kinase (ALK) 3 (ALK3(QD)), cells were harvested at $36 \mathrm{~h}$ post-transfection. To evaluate the levels of hepcidin mRNA, HepG2 cells and Hepa1-6 cells were treated for $24 \mathrm{~h}$ with or without trichostatin A (TSA: $0.1 \mu \mathrm{g} / \mathrm{mL}$; Wako, Tokyo, Japan), an inhibitor of class I and II histone deacetylases (Gräff and Tsai, 2013), RNAlater (0.1 or $1 \%$; Life Technologies, Carlsbad, CA, USA) to denature RNase at a controlled pH (Zaitoun et al., 2010) or MG-132 (20 $\mu \mathrm{M}$; EMD Millipore, Billerica, MA, USA), a proteasome inhibitor (Tsubuki et al., 1993). In Hepa1-6 cells, treatment with MG-132 at $20 \mu \mathrm{M}$ caused detachment of the cells from culture dish, and, therefore, we also treated with MG-132 at $10 \mu \mathrm{M}$.

\subsection{RNA isolation, RT-PCR and RT-quantitative PCR}


Total RNA was isolated from livers and cells, and cDNA was synthesized using TRIZOL (Invitrogen, Grand Island, NY, USA) and ReverTra Ace qPCR RT kit (Toyobo, Osaka, Japan), respectively, according to the manufacturers' protocols. The cDNA reverse-transcribed from 5 or $20 \mathrm{ng}$ of total RNA was used as a template for conventional reverse transcription-polymerase chain reaction (RT-PCR) or RTquantitative PCR (RT-qPCR) using SYBR Green I (Thunderbird SYBR qPCR mix, Toyobo, Osaka, Japan) as described previously (Asano et al., 2013). The oligonucleotide primers for the conventional RT-PCR and RT-qPCR are presented in Table 1. The Ct value was determined, and the abundance of gene transcripts was analyzed using the $\Delta \Delta \mathrm{Ct}$ method using glyceraldehyde-3-phosphate dehydrogenase (Gapdh) as the normalization gene (Duran et al., 2005).

\subsection{Plasmids and reporter assays}

Plasmids were obtained as follows: BRE-luc reporter plasmids (Korchynskyi and ten Dijke, 2002) was from Dr. P. ten Dijke, and ALK3(QD) (Imamura et al., 1997) was obtained from Dr. K. Miyazono. The DNA fragment spanning from -2018 bp to $-35 \mathrm{bp}$ of the mouse hepcidin (Hamp1) promoter was amplified and cloned into the basic vector pGL4 containing the firefly luciferase reporter (Hepcidin (-2018)-luc) with nt +1 as the translation initiation site. The product was verified through nucleotide sequencing. Luciferase-based reporter assays were conducted as described previously (Murakami et al., 2009). Cells were transiently transfected with the indicated expression vectors, reporter construct and a plasmid expressing $\beta$-galactosidase under the control cytomegalovirus promoter (pCMV- $\beta \mathrm{Gal})$. Equal amounts of DNA were transfected in each experiment and adjusted with empty vector. Luciferase activity was normalized to the $\beta$-galactosidase activity, and the luciferase activity in the cell lysate transfected without BMP treatment or with the empty vector was set at 1 . 


\subsection{Statistical analyses}

Data are expressed as the mean \pm standard error of the mean (SEM). Data on gene expression were log-transformed to provide an approximation of a normal distribution before analysis. Differences between control cells and BMP2-treated cells, between cycloheximide-treated and untreated cells, and between LDN-193189-treated and untreated cells were examined using unpaired $t$-tests. Differences of $P<0.05$ were considered significant.

\section{Results and discussion}

\subsection{Hepcidin expression is lower in cell lines than in liver and primary hepatocytes}

Hepcidin expression was examined in mouse and rat livers, rat primary hepatocytes and the human HepG2 and mouse Hepa1-6 liver cell lines. To compare the hepcidin expression levels, we designed PCR primers to amplify both mouse hepcidin (Hamp1) and rat hepcidin (Fig. 1A), and both human hepcidin and mouse hepcidin (Fig. 1B). Significant hepcidin expression was detected in livers and primary hepatocytes, but the levels of hepcidin expression in HepG2 cells and Hepa1-6 cells was lower or below the limit of detection. Gapdh and hypoxanthine phosphoribosyltransferase 1 (Hprt1), house-keeping genes, were individually amplified by use of common PCR primers applicable to human, mouse and rat Gapdh and Hprt1. The Gapdh levels tended to be higher in HepG2 cells and Hepa1-6 cells than in the livers and primary hepatocytes, and the Hprt1 levels were higher in primary hepatocytes and liver cell lines (Fig. 1C).

We also examined hepcidin expression by RT-qPCR analyses (Fig. 2). Consistent with the RT-PCR analyses (Fig. 1), hepcidin expression level in primary hepatocytes was as high as that in the livers (Fig. 2A), whereas hepcidin expression level was below 
detection limit in the liver cell lines, including HepG2 cells and Hepa1-6 cells (Fig. 2B). In some samples, we could detect significant fluorescence in qPCR more than 35 cycles in HepG2 cells, but it was not reproducible (data not shown). Hepcidin mRNA level has been clearly detected in liver cell lines including HepG2 cells (Ravasi et al., 2012); the discrepancy could be due to the differences of the sensitivity of RT-qPCR analyses. The RT-qPCR analyses for Gapdh and Hprt1 indicated clear expression in all samples (Fig. 2C and D); similar to the RT-PCR analyses (Fig. 1), expression level in the liver samples tended to be lower than that in the primary hepatocytes and liver cell lines. All these results suggest that hepcidin expression levels in liver cell lines are lower than those in the livers and primary hepatocytes, and that the lower expression of hepcidin in the liver cell lines is not due to a non-specific decrease in gene transcript levels.

There are several possible explanations for the lower hepcidin mRNA levels in the liver cell lines. Hepcidin mRNA is negatively regulated by Tmprss6, a transmembrane matriptase-2 (Du et al., 2008); the increase in Tmprss6 mRNA levels in response to BMP treatment is delayed compared to the up-regulation of hepcidin expression, indicating a negative feedback loop to avoid excess hepcidin expression (Meynard et al., 2011). Because the lower expression of hepcidin in the liver cell lines likely results from higher expression of Tmprss6, we examined the Tmprss6 expression level in liver cell lines. However, Tmprss6 expression was undetectable in the liver cell lines (Fig. 1D). Thus, the low level of hepcidin expression in the liver cell lines is not due to high levels of Tmprss6.

We also examined the potential roles of histone deacetylase activation and mRNA instability in the low expression of hepcidin in liver cell lines. Treatment with TSA robustly increased the expression of hepcidin in HepG2 cells but not in Hepa1-6 cells, although the expression level in cells without TSA treatment was near the limit of 
detection (Fig. 3A). Hepcidin expression was also induced by treatment with an RNase inhibitor in HepG2 cells but not in Hepa1-6 cells (Fig. 3B). Unlike Hepa1-6 cells, transcriptional repression due to histone deacetylation, mRNA instability or both may be responsible for the low levels of hepcidin in HepG2 cells. We further examined the effect of MG-132 on hepcidin expression. Treatment with MG-132 increased hepcidin transcription in HepG2 cells but not in Hepa1-6 cells (Fig. 3C). These results suggest the different reason underlying the lower expression level of hepcidin between HepG2 cells and Hepa1-6 cells. Future studies are needed to clarify the reason of the lower expression of hepcidin in Hepa1-6 cells. Additionally, histone acetylation within the hepcidin promoter and hepcidin mRNA instability should be also evaluated to clarify the relation to the silencing of hepcidin in HepG2 cells. Furthermore, the molecule(s) that positively regulate hepcidin, which is degraded by proteasome, should be identified in HepG2 cells.

As described above, the activation of hepcidin expression by the BMP pathway is well known (Babitt et al., 2006, 2007; Muckenthaler, 2008; Lee and Beutler, 2009). We also evaluated hepcidin expression in response to BMP treatment and the effect of cycloheximine, a protein synthesis inhibitor, in rat primary hepatocytes. BMP increased hepcidin expression 4.5-fold, and cycloheximide partially blocked the up-regulation of hepcidin expression (Fig. 4). The results indicate that BMP-induced hepcidin expression is partially a direct event, and that it is also enhanced through de novo protein synthesis; the results clearly disagree with a previous study using HepG2 cells in which cycloheximide did not affect BMP-induced hepcidin expression (Babitt et al., 2006). The contradicting conclusions are possibly due to the different cell types used in the studies.

The BMP-regulated expression of hepcidin has been studied in various systems, 
including the liver cell lines such as HepG2, Hep3B and Huh7 cells (Babitt et al., 2006, 2007; Truksa et al., 2007, 2009; Mleczko-Sanecka et al., 2010). The Lin group has examined hepcidin mRNA by RT-qPCR analyses, and their studies revealed that treatment with BMP increased the expression of hepcidin by 50 to 1100-fold and 12 to 25-fold in Hep3B cells and HepG2 cells, respectively. An approximately 8-fold induction was detected in mouse and rat primary hepatocytes, and intraperitoneal injection of BMP resulted in only a 1.3 to 2 -fold increase in hepatic hepcidin expression (Babitt et al., 2006, 2007; Andriopoulos et al., 2009; Corradini et al., 2009, 2010; Theurl et al., 2011). One explanation for the larger effect BMP treatment on hepcidin expression in the liver cell lines may be related to a lower basal expression level; the magnitude of the increase in the hepcidin mRNA copy number in response to BMP treatment relative to the total hepcidin mRNA is larger when the basal expression is lower. Examining hepcidin mRNA in liver cell lines can allow one to overlook factor(s) that positively and negatively affect hepcidin expression.

\subsection{Hepcidin transcription can be examined in cell lines}

Primary hepatocytes are suitable for examining hepcidin mRNA levels, but they are inappropriate for studying the transcriptional regulation of hepcidin using a reporter gene; it is generally difficult to transfect primary cells with plasmid DNA, although plasmid DNA can be highly transfected in primary cells by use of a special apparatus (Gresch and Altrogge, 2012). In contrast, cell lines can be easily transfected with plasmid DNA, and the transcriptional regulation of hepcidin has been examined by luciferase-based reporter assays in many studies (Truksa et al., 2009; Mleczko-Sanecka et al., 2010; Goodnough et al., 2012; Pandur et al., 2013). Consistent with the results of previous studies, the expression of hepcidin(-2018)-luc was significantly increased by BMP treatment in HepG2 cells $(P<0.01)$ and was inhibited by pretreatment with LDN-193189; both basal expression of the luciferase and the induced expression in 
response to BMP treatment were significantly decreased $(P<0.01$, Fig. 5A). Similar results were obtained in Hepa1-6 cells (Fig. 5B). Furthermore, the enhanced transcription of hepcidin(-2018)-luc was significantly elicited by the forced expression of ALK3(QD), a constitutively active BMP type I receptor (Imamura et al., 1997) $(P<$ 0.01, Fig. 5C). These results confirm previous results that showed that BMP-induced hepcidin transcription is evaluated in liver cell lines.

BRE-luc, which is derived from the promoter region of inhibitor of differentiation 1 (Id1), a BMP target gene, is a representative reporter that transmits canonical BMP signaling (Korchyniskyi and ten Dijke, 2002). Provided that hepcidin transcription is stimulated by the BMP pathway in liver cells (Fig. 5A-C), we expected that not only hepcidin(-2018)-luc but also BRE-luc is transcriptionally stimulated by the BMP pathway. However, the BMP-induced transcriptional activation of BRE-luc was not detected in HepG2 cells. 3T3-L1 cells and C2C12 cells are non-liver cells that can transmit canonical BMP signaling (Korchyniskyi and ten Dijke, 2002; Rebbapragada et al., 2003); in these cells, BMP treatment increased expression of BRE-luc and hepcidin(-2018)-luc ( $P<0.01$, Fig. 5D, data not shown). The higher response of hepcidin(-2018)-luc than BRE-luc was also detected when the BMP signal was transmitted by ALK3(QD) expression, although ALK3(QD) expression significantly increased expression of hepcidin(-2018)-luc $(P<0.01$, Fig. 5E). The results suggest that it is difficult to evaluate BMP signaling by BRE-luc and that the hepcidin promoter senses exogenous BMP with high sensitivity in liver cell lines, thus extending the current understanding of how hepcidin expression is regulated by the BMP pathway.

\section{Conclusions}

The present study revealed that 1) compared with expression in livers and primary hepatocytes, hepcidin expression levels are lower in liver cell lines, 2) the activation of 
histone deacetylase and the accelerated degradation of mRNA or protein(s) may be involved in the lower expression levels of hepcidin in HepG2 cells, and 3) the transcriptional regulation of hepcidin, which is highly responsive to $\mathrm{BMP}$, can be evaluated in liver cell lines. We conclude that primary hepatocytes should be used to examine the regulation of hepcidin expression at the mRNA level. In addition, liver cell lines such as HepG2 cells and Hepa1-6 cells should be limited to studies that aim to evaluate the transcriptional regulation of hepcidin.

\section{Acknowledgements}

We thank Drs. K. Miyazono and P. ten Dijke for providing plasmids. This work was partly supported by a research project grant awarded by the Azabu University. 


\section{References}

Andriopoulos B Jr, Corradini E, Xia Y, Faasse SA, Chen S, Grgurevic L, Knutson MD, Pietrangelo A, Vukicevic S, Lin HY, Babitt JL. BMP6 is a key endogenous regulator of hepcidin expression and iron metabolism. Nat Genet. 2009 41:482-7.

Asano H, Yamada T, Hashimoto O, Umemoto T, Sato R, Ohwatari S, Kanamori Y, Terachi T, Funaba M, Matsui T. Diet-induced changes in Ucp1 expression in bovine adipose tissues. Gen Comp Endocrinol. 2013 184:87-92.

Babitt JL, Huang FW, Wrighting DM, Xia Y, Sidis Y, Samad TA, Campagna JA, Chung RT, Schneyer AL, Woolf CJ, Andrews NC, Lin HY. Bone morphogenetic protein signaling by hemojuvelin regulates hepcidin expression. Nat Genet. 2006 38:531-9.

Babitt JL, Huang FW, Xia Y, Sidis Y, Andrews NC, Lin HY. Modulation of bone morphogenetic protein signaling in vivo regulates systemic iron balance. J Clin Invest. 2007 117:1933-9.

Corradini E, Garuti C, Montosi G, Ventura P, Andriopoulos B Jr, Lin HY, Pietrangelo A, Babitt JL. Bone morphogenetic protein signaling is impaired in an HFE knockout mouse model of hemochromatosis. Gastroenterology. 2009 137:1489-97.

Corradini E, Schmidt PJ, Meynard D, Garuti C, Montosi G, Chen S, Vukicevic S, Pietrangelo A, Lin HY, Babitt JL. BMP6 treatment compensates for the molecular defect and ameliorates hemochromatosis in Hfe knockout mice. Gastroenterology. 2010 139:1721-9.

Cuny GD, Yu PB, Laha JK, Xing X, Liu JF, Lai CS, Deng DY, Sachidanandan C, Bloch KD, Peterson RT. Structure-activity relationship study of bone morphogenetic protein (BMP) signaling inhibitors. Bioorg Med Chem Lett. 2008 18:4388-92.

De Domenico I, Ward DM, Langelier C, Vaughn MB, Nemeth E, Sundquist WI, Ganz T, Musci G, Kaplan J. The molecular mechanism of hepcidin-mediated ferroportin down-regulation. Mol Biol Cell. 2007 18:2569-78. 
Du X, She E, Gelbart T, Truksa J, Lee P, Xia Y, Khovananth K, Mudd S, Mann N, Moresco EM,Beutler E, Beutler B. The serine protease TMPRSS6 is required to sense iron deficiency. Science. 2008 320:1088-92.

Duran EM, Shapshak P, Worley J, Minagar A, Ziegler F, Haliko S, Moleon-Borodowsky I, Haslett PA. Presenilin-1 detection in brain neurons and FOXP3 in peripheral blood mononuclear cells: normalizer gene selection for real time reverse transcriptase pcr using the deltadeltaCt method. Front Biosci. 2005 10:2955-65.

Ganz T, Nemeth E. Hepcidin and iron homeostasis. Biochim Biophys Acta. 2012 1823:1434-43.

Goodnough JB, Ramos E, Nemeth E, Ganz T. Inhibition of hepcidin transcription by growth factors. Hepatology. 2012 56:291-9.

Gräff J, Tsai LH. Histone acetylation: molecular mnemonics on the chromatin. Nat Rev Neurosci. 2013 14:97-111.

Gresch O, Altrogge L. Transfection of difficult-to-transfect primary mammalian cells. Methods Mol Biol. 2012 801:65-74.

Imamura T, Takase M, Nishihara A, Oeda E, Hanai J, Kawabata M, Miyazono K. Smad6 inhibits signalling by the TGF- $\beta$ superfamily. Nature. 1997 389:622-6.

Kautz L, Meynard D, Monnier A, Darnaud V, Bouvet R, Wang RH, Deng C, Vaulont S, Mosser J, Coppin H, Roth MP. Iron regulates phosphorylation of Smad1/5/8 and gene expression of Bmp6, Smad7, Id1, and Atoh8 in the mouse liver. Blood. 2008 112:1503-9.

Korchynskyi O, ten Dijke P. Identification and functional characterization of distinct critically important bone morphogenetic protein-specific response elements in the Id1 promoter. J Biol Chem. 2002 277:4883-91.

Laftah AH, Ramesh B, Simpson RJ, Solanky N, Bahram S, Schümann K, Debnam ES, Srai SK. Effect of hepcidin on intestinal iron absorption in mice. Blood. 2004 103:3940-4. 
Lee PL, Beutler E. Regulation of hepcidin and iron-overload disease. Annu Rev Pathol. 2009 4:489-515.

Meynard D, Kautz L, Darnaud V, Canonne-Hergaux F, Coppin H, Roth MP. Lack of the bone morphogenetic protein BMP6 induces massive iron overload. Nat Genet. 2009 41:478-81.

Mleczko-Sanecka K, Casanovas G, Ragab A, Breitkopf K, Müller A, Boutros M, Dooley S, Hentze MW, Muckenthaler MU. SMAD7 controls iron metabolism as a potent inhibitor of hepcidin expression. Blood. 2010 115:2657-65.

Muckenthaler MU. Fine tuning of hepcidin expression by positive and negative regulators. Cell Metab. 2008 8:1-3.

Meynard D, Vaja V, Sun CC, Corradini E, Chen S, López-Otín C, Grgurevic L, Hong CC, Stirnberg M, Gütschow M, Vukicevic S, Babitt JL, Lin HY. Regulation of TMPRSS6 by BMP6 and iron in human cells and mice. Blood. 2011 118:747-56.

Murakami M, Kawachi H, Ogawa K, Nishino Y, Funaba M. Receptor expression modulates the specificity of transforming growth factor- $\beta$ signaling pathways. Genes Cells. 2009 14:469-82.

Nemeth E, Tuttle MS, Powelson J, Vaughn MB, Donovan A, Ward DM, Ganz T, Kaplan J. Hepcidin regulates cellular iron efflux by binding to ferroportin and inducing its internalization. Science. 2004 306:2090-3.

Pandur E, Sipos K, Grama L, Nagy J, Poór VS, Sétáló G, Miseta A, Fekete Z. Prohepcidin binds to the HAMP promoter and autoregulates its own expression. Biochem J. 2013 451:301-11.

Ravasi G, Pelucchi S, Trombini P, Mariani R, Tomosugi N, Modignani GL, Pozzi M, Nemeth E, Ganz T, Hayashi H, Barisani D, Piperno A. Hepcidin expression in iron overload diseases is variably modulated by circulating factors. PLoS One. 2012 $7: \mathrm{e} 36425$.

Rebbapragada A, Benchabane H, Wrana JL, Celeste AJ, Attisano L. Myostatin signals 
through a transforming growth factor $\beta$-like signaling pathway to block adipogenesis. Mol Cell Biol. 2003 23:7230-42.

Theurl I, Schroll A, Sonnweber T, Nairz M, Theurl M, Willenbacher W, Eller K, Wolf D, Seifert M, Sun CC, Babitt JL, Hong CC, Menhall T, Gearing P, Lin HY, Weiss G. Pharmacologic inhibition of hepcidin expression reverses anemia of chronic inflammation in rats. Blood. 2011 118:4977-84.

Truksa J, Lee P, Beutler E. Two BMP responsive elements, STAT, and bZIP/HNF4/COUP motifs of the hepcidin promoter are critical for BMP, SMAD1, and HJV responsiveness. Blood. 2009 113:688-95.

Truksa J, Peng H, Lee P, Beutler E. Bone morphogenetic proteins 2, 4, and 9 stimulate murine hepcidin 1 expression independently of Hfe, transferrin receptor 2 (Tfr2), and IL-6. Proc Natl Acad Sci U S A. 2006 103:10289-93.

Tsubuki S, Kawasaki H, Saito Y, Miyashita N, Inomata M, Kawashima S. Purification and characterization of a Z-Leu-Leu-Leu-MCA degrading protease expected to regulate neurite formation: a novel catalytic activity in proteasome. Biochem Biophys Res Commun. 1993 196:1195-201.

Zaitoun I, Erickson CS, Schell K, Epstein ML. Use of RNAlater in fluorescence-activated cell sorting (FACS) reduces the fluorescence from GFP but not from DsRed. BMC Res Notes. 2010 3:328. 


\section{Figure legends}

Fig. 1. Hepcidin expression in the liver, primary hepatocytes and liver cell lines

The cDNA was prepared from total RNA from mouse and rat livers, rat primary hepatocytes and the liver cell lines HepG2 and Hepa1-6. RT-PCR was performed using primers to detect (A) mouse and rat hepcidin using mrHepcidin primer set, (B) human and mouse hepcidin using mhHepcidin primer set, (C) human, mouse and rat Gapdh and Hprt1 and (D) human, mouse and rat Tmprss6. The PCR products were electrophoresed on $2 \%$ agarose gels and stained with ethidium bromide. A representative result is shown.

Fig. 2. Lower hepcidin expression in liver cell lines than in the liver and primary hepatocytes

The cDNA was prepared from total RNA from mouse and rat livers, rat primary hepatocytes and the liver cell lines HepG2 and Hepa1-6. RT-qPCR was performed using primers to detect (A) mouse and rat hepcidin using mrHepcidin primer set, (B) human and mouse hepcidin using mhHepcidin primer set, (C) human, mouse and rat Gapdh and (D) human, mouse and rat Hprt1. The amplification plots are shown. Note that cDNA from HepG2 cells and Hepa1-6 cells was not amplified (B).

Fig. 3. Altered expression of hepcidin by histone deacetylases, RNase and the proteasome in HepG2 cells but not in Hepa1-6 cells

HepG2 cells were treated with TSA (A), RNase inhibitor (B) or MG-132 (C) as described in the Materials and Methods. The treatments were performed in quadruplicate. The hepcidin (upper) and Gapdh (lower) expression levels were examined by RT-PCR. The PCR products were electrophoresed on 2\% agarose gels and stained with ethidium bromide. A representative result is shown.

Fig. 4. Hepcidin expression and transcription in response to BMP2 in liver cells 
Rat primary hepatocytes were treated with or without BMP2 in the presence $(+)$ or absence (-) of cycloheximide (CHX). Hepcidin expression examined by RT-qPCR using rHepcidin primer set was normalized to Gapdh expression, which was quantified by use of rGapdh primer set. The expression level in cells treated without BMP2 or cycloheximide was set at $1 . * *: P<0.01$ vs. cells treated without BMP2. $+: P<0.01 v s$. cells treated with BMP2 and without cycloheximide.

Fig. 5. Hepcidin expression and transcription in response to BMP2 in liver cells HepG2 cells (A) and Hepa1-6 cells (B) were transiently transfected with Hepcidin(-2018)-luc and pCMV- $\beta$ Gal and treated with or without BMP2 in the presence (+) or absence (-) of LDN-193189. (C) Hepcidin(-2018)-luc, ALK3(QD) and pCMV- $\beta$ Gal were transfected into the indicated cells. (D) The indicated reporter gene and pCMV- $\beta$ Gal were transfected in HepG2 and 3T3-L1 cells, and the cells were treated with or without BMP2. (E) HepG2 cells were transfected with the indicated reporter, ALK3(QD) and pCMV- $\beta$ Gal. Luciferase activity was normalized to $\beta$-galactosidase activity, and luciferase activity in the cell lysates in the absence of BMP2, ALK3(QD) and LDN-193189 was set at 1. Data are expressed as the mean \pm S.E. $(\mathrm{n}=3) . * *: P<0.01 v s$. cells treated without BMP2. $\ddagger: P<0.01$ vs. cells treated without LDN-193189. 
Table 1. Oligonucleotide PCR primers for RT-PCR and RT-qPCR

\begin{tabular}{|c|c|c|c|}
\hline & \multicolumn{2}{|c|}{ Oligonucleotide } & \multirow{2}{*}{$\begin{array}{l}\text { GenBank } \\
\text { accession number }\end{array}$} \\
\hline & 5'-primer & 3'-primer & \\
\hline \multicolumn{4}{|c|}{ RT-PCR and qPCR: } \\
\hline Gapdh & 5'- TTCATTGACCTCAACTACATGGT -3' & 5'- GCTAAGCAGTTGGTGGTGCAGGA -3' & $\begin{array}{l}\text { NM_002046 (human) } \\
\text { NM_008084 (mouse) } \\
\text { NM_017008 (rat) }\end{array}$ \\
\hline Hprt1 & 5'- ATGGGAGGCCATCACATTG -3' & 5'- CTTTCCAGTTAAAGTTGAGAGATCA -3' & $\begin{array}{l}\text { NM_000194 (human) } \\
\text { NM_013556 (mouse) } \\
\text { NM_012583 (rat) }\end{array}$ \\
\hline mhHepcidin $^{1}$ & 5'- TGCCTCCTGCTCCTCCTCCT -3' & 5'- GCAGAAAATGCAGATGGGGAAGT -3’ & $\begin{array}{l}\text { NM_021175 (human) } \\
\text { NM_032541 (mouse) }\end{array}$ \\
\hline mrHepcidin $^{2}$ & 5'- GCTGCCTGTCTCCTGCTT -3' & 5' - TTACAGCATTTACAGCAGAAGAGG -3' & $\begin{array}{l}\text { NM_053469 (rat) } \\
\text { NM_032541 (mouse) }\end{array}$ \\
\hline \multicolumn{4}{|l|}{ RT-PCR: } \\
\hline Tmprss6 & 5'- CACTGTGACTGTGGCCTCCAGG -3' & 5' - CGTCGTAGTCATGGCTGTCCTC -3' & $\begin{array}{l}\text { NM_153609 (human) } \\
\text { NM_027902 (mouse) } \\
\text { NM_001130556 (rat) }\end{array}$ \\
\hline \multicolumn{4}{|l|}{ RT-qPCR: } \\
\hline rGapdh & 5'- ACAACTTTGGCATCGTGGA -3' & 5'- CTTCTGAGTGGCAGTGATGG -3' & NM_017008 (rat) \\
\hline rHepcidin & 5'- GCTGCCTGTCTCCTGCTT -3' & 5'- AGCCGTAGTCTGTCTCGTCT -3' & NM_053469 (rat) \\
\hline
\end{tabular}




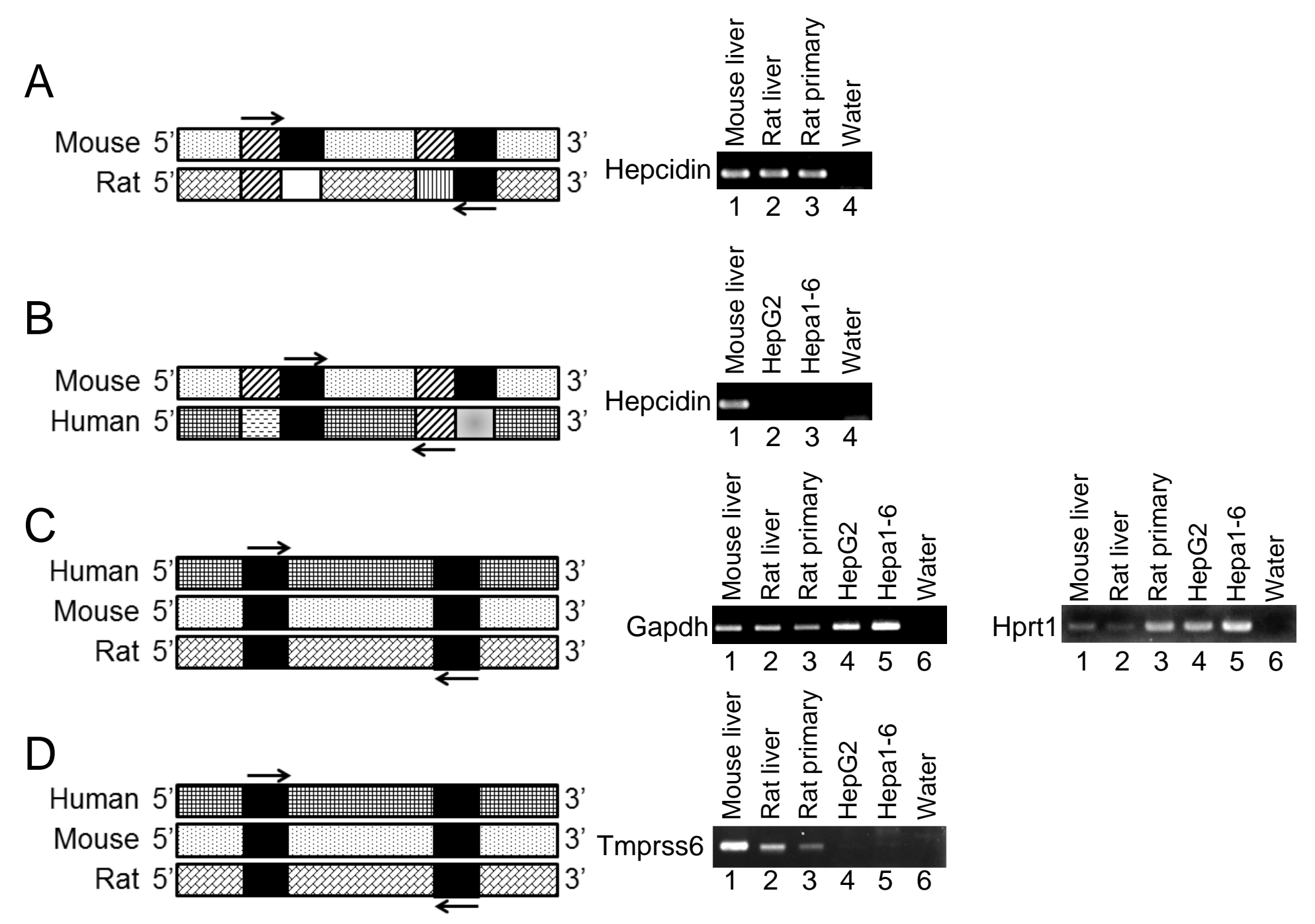


A

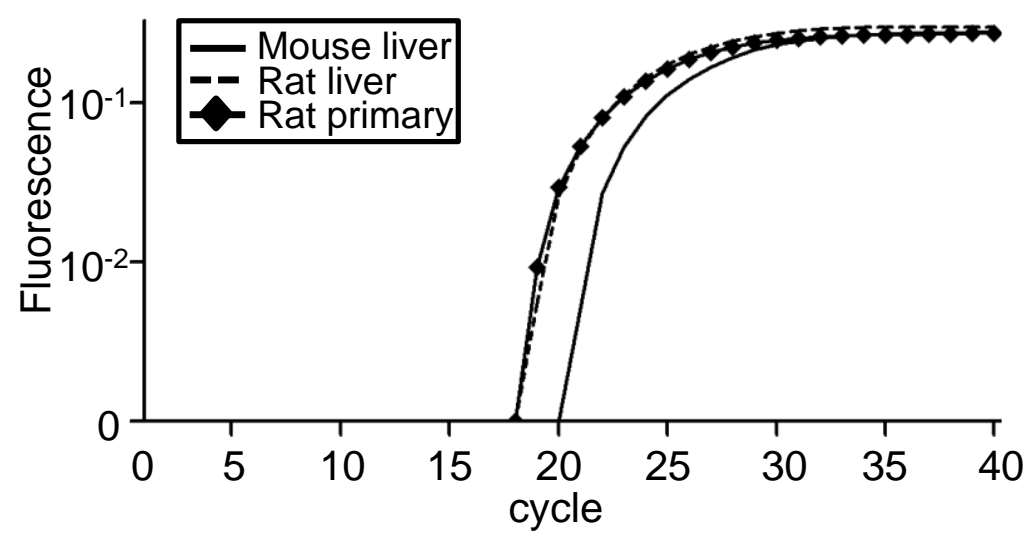

C

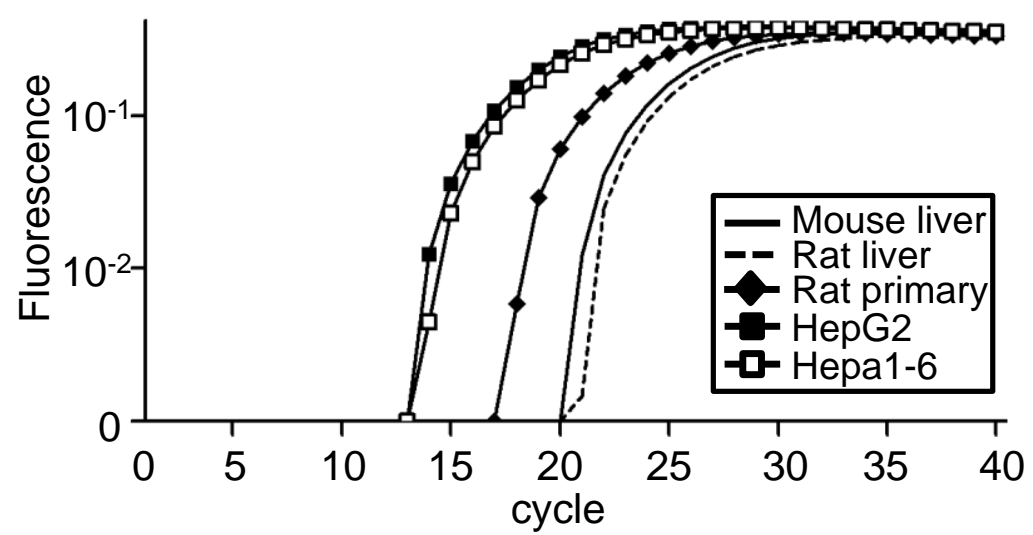

B

Hepcidin

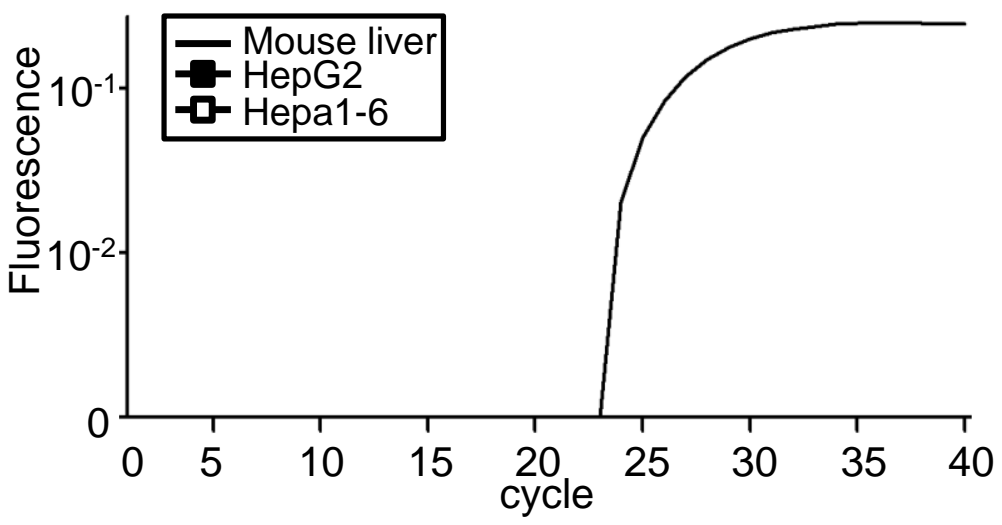

D

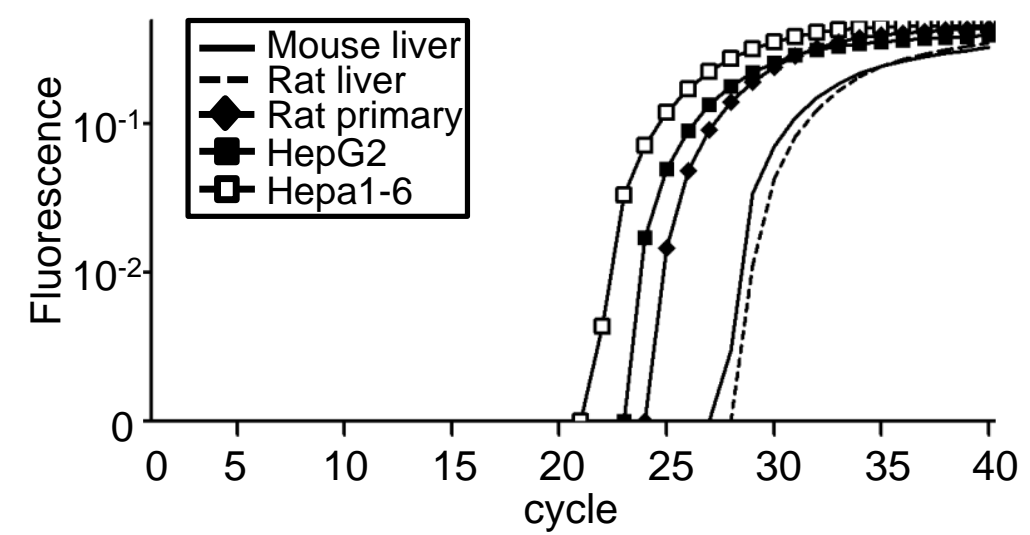



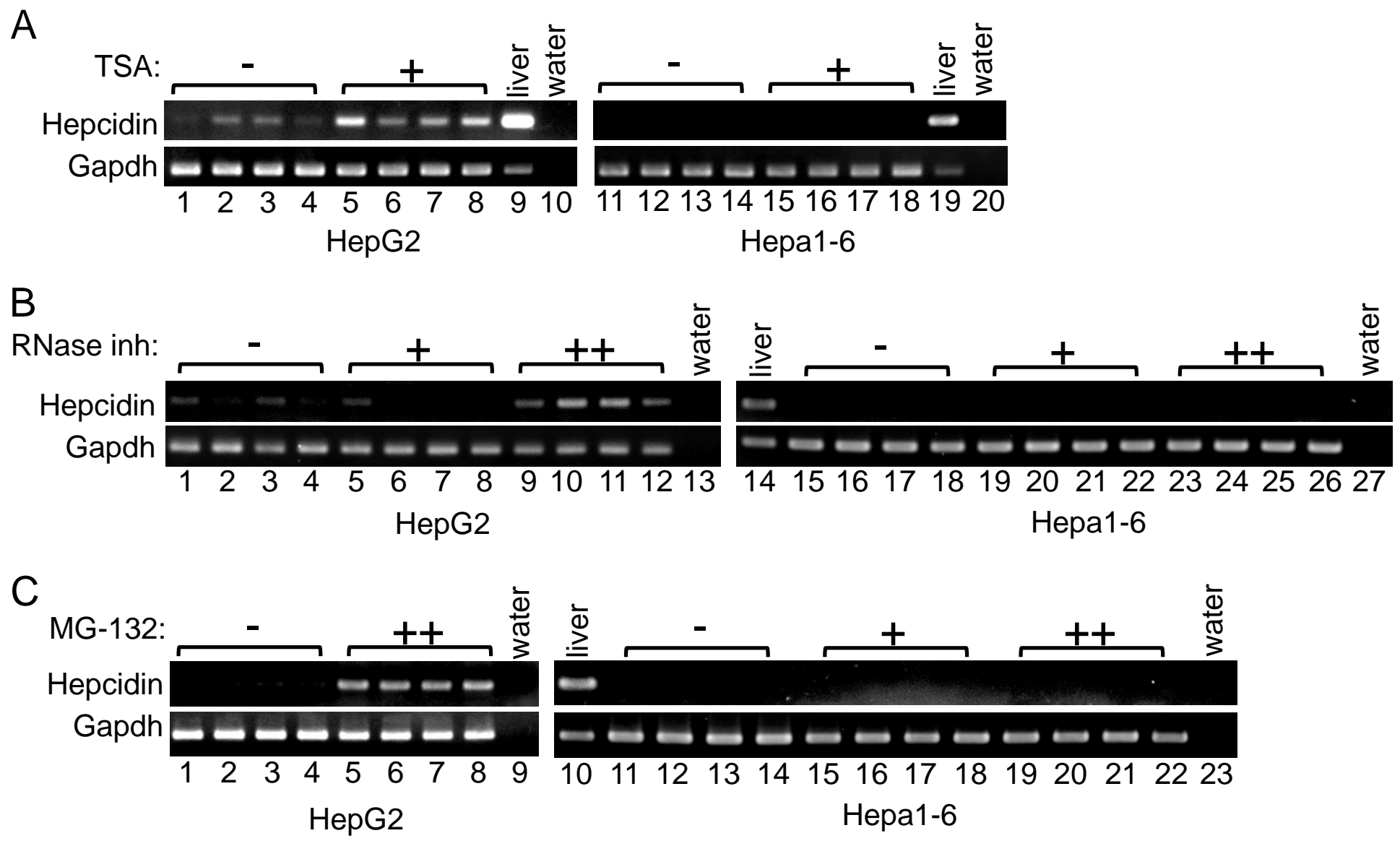


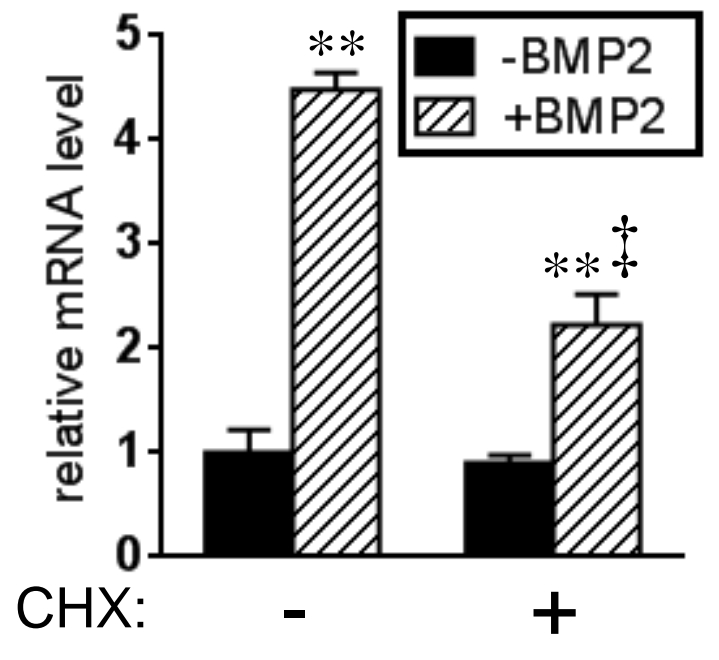


A HepG2

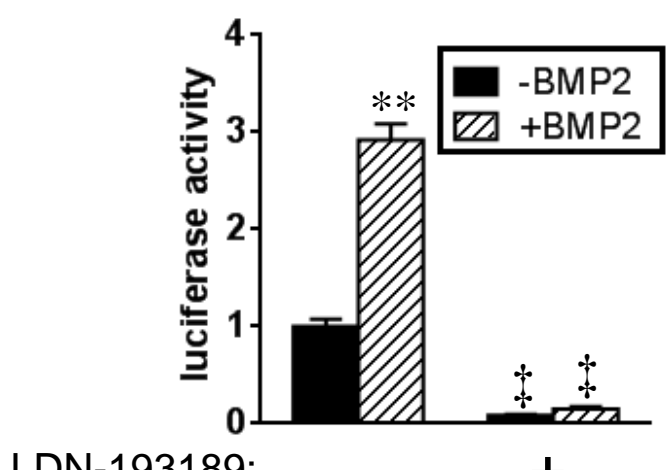

LDN-193189:

D

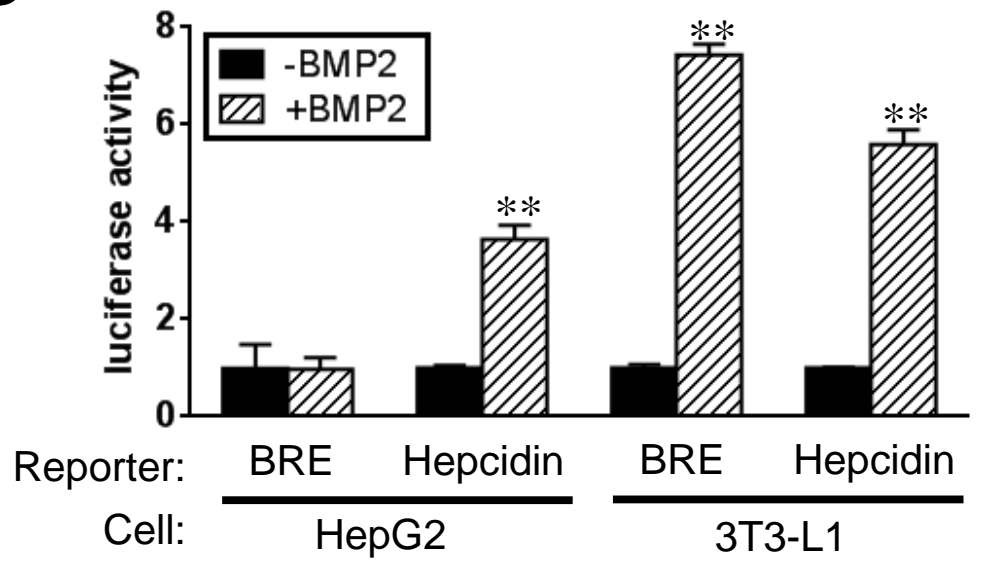

B

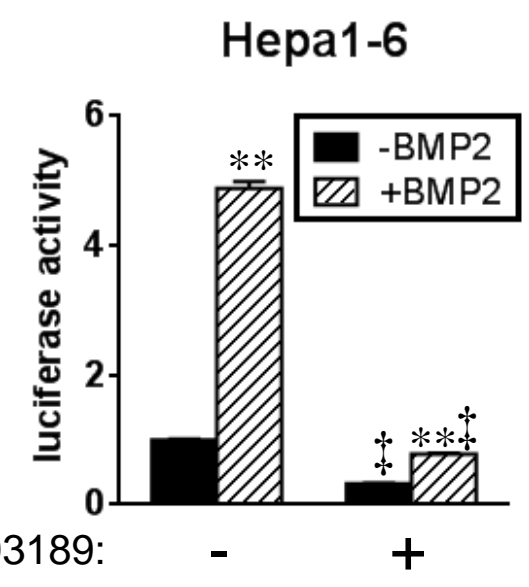

C

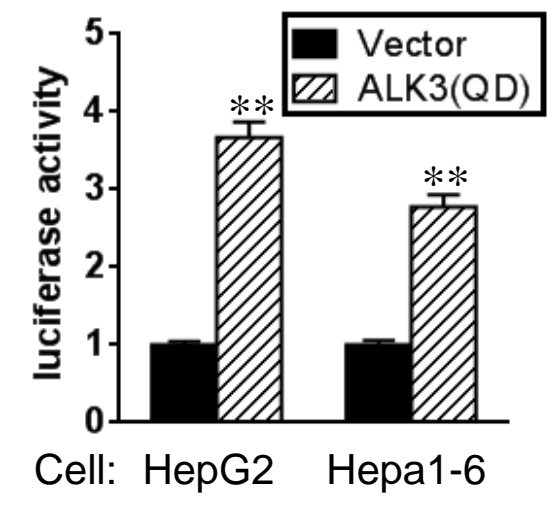

$E$

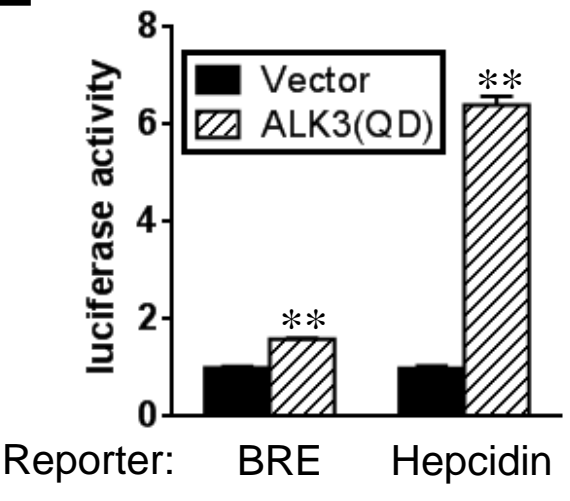

Reporter: BRE Hepcidin 